\title{
COVID-19 in hemodialysis patients: a single-center experience in Istanbul
}

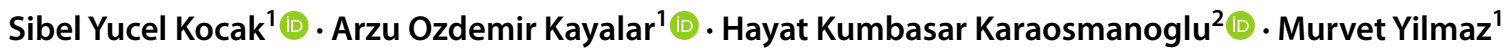

Received: 23 September 2020 / Accepted: 19 February 2021 / Published online: 6 March 2021

(c) The Author(s), under exclusive licence to Springer Nature B.V. part of Springer Nature 2021

\begin{abstract}
Objective Coronavirus disease 2019 (COVID-19) causes a wide spectrum of symptoms, from asymptomatic conditions to severe inflammatory response. Hemodialysis (HD) patients have a higher risk for developing severe COVID-19 because of older age, multiple co-morbid conditions, and impaired immune system compared to the general population. As little is known about these special groups, we evaluated the clinical characteristics and outcomes of HD patients with COVID- 19. Methods All hospitalized HD patients with COVID 19 between March 11, 2020 and May 31, 2020 were included in the study. The composite end-points consisted of admission to the intensive care unit (ICU), discharging or death were analysed. Demographic, clinical, laboratory, and treatment data were retrieved and compared between survivors and nonsurvivors.

Results A total of 45 patients (median age $65.33 \pm 12.22$, 24 female, 53.96 \pm 40.68 ) were enrolled and of whom 14 were admitted to ICU and overall 14 (31.1\%) have died. Hypertension was the most common comorbidity and fever (60\%), dyspnea (55.6\%) and cough (53.3\%) were predominant symptoms at admission. 8.8\% of patients developed severe complications (acute respiratory distress syndrome, macrophage activation syndrome) and secondary infection was observed in $51.1 \%$ of the patients. Elevation in the level of inflammatory markers, lactate dehydrogenase, liver enzymes, troponin, creatine kinase, and decrease in lymphocyte count and serum albumin level were observed in non-survivors compared with survivors throughout the clinical course. No significant difference was observed in the score of chest CT performed on the day of hospitalization for the survivors and non-survivors.
\end{abstract}

Conclusion Mortality of COVID-19 in HD patients is high and follow up of certain laboratory parameters can help to predict the prognosis of the patients.

Keywords COVID-19 $\cdot$ Hemodialysis $\cdot$ Mortality

Sibel Yucel Kocak

fsibelkocak@yahoo.com

Arzu Ozdemir Kayalar

arzukayalar@yahoo.com

Hayat Kumbasar Karaosmanoglu

drhayat1@ hotmail.com

Murvet Yilmaz

murvetyilmaz@hotmail.com

1 Department of Nephrology, University of Health Sciences, Bakırkoy Dr. Sadi Konuk Education and Research Hospital, Zuhuratbaba, Tevfik Sağlam Cad. No: 11, 34147 Bakırköy, Istanbul, Turkey

2 Department of Infectious Diseases, University of Health Sciences, Bakirkoy Dr. Sadı Konuk Education and Research Hospital, Zuhuratbaba, Tevfik Sağlam Cad. No: 11, 34147 Bakırköy, Istanbul, Turkey

\section{Introduction}

Novel Coronavirus disease 2019 (COVID-19) has spread all over the world after the first identification of cases in the Wuhan district of China, on December 2019 and announced as a pandemic by the World Health Organization in March 2020. COVID-19 caused by severe acute respiratory syndrome coronavirus 2 (SARS-CoV-2) affects the respiratory, gastrointestinal, cardiovascular, and central nervous systems and causes a mild to moderate illness characterized by fever and respiratory symptoms, with or without evidence of pneumonia in $80 \%$ of the patients.

Recent studies show that as many as $25 \%$ of patients who are infected remain asymptomatic and viral shedding may begin up to $48 \mathrm{~h}$ before symptoms appear [1-3]. Advanced age and underlying diseases (hypertension, diabetes mellitus, cardiovascular disease, and cerebrovascular disease) 
are risk factors to develop severe pneumonia with hypoxia, acute respiratory distress syndrome, and multiorgan failure requiring intensive care unit (ICU) admission for respiratory and organ support $[4,5]$.

In this regard, patients with CKD, especially for dialyzed patients who are mostly elderly, immunosuppressed with multiple co-morbid conditions are more vulnerable to COVID-19 infection. Also, dialyzed patients have a high risk for exposure to the virus, because they must apply to the hemodialysis center twice or thrice a week and come together with many patients and dialysis staff in the facility. In this issue, there are several reports from China, New York, and many European countries which have different study designs [6-8]. and data were limited. We aimed to describe the presentation, clinical characteristics, management, early outcomes of hospitalized dialyzed patients and to identify prognostic markers.

\section{Materials and methods}

A total of 45 patients receiving HD were included into the study among 1958 patients with confirmed and suspected COVID-19 who were admitted to Bakirkoy Dr. Sadi Konuk Educational and Research Hospital, Istanbul, Turkey between March 11 and May 31, 2020. Patients receiving dialysis less than 3 months and $<18$ years old were excluded from the study. At data cut off, all of the patients either died or were discharged, hence resulting in a survivor group and a non-survivor group. The clinical features and outcomes were evaluated and demographic, clinical, laboratory and management data were compared between survivors and non-survivors. Ethic committee approval was obtained from our hospital.

Since we care not only hospitalized acute or chronic hemodialysis patients but also approximately 44 patients on maintenance dialysis in our facility, HD patients with COVID-19 scheduled for the dialysis during last shift of each day. If they need urgent dialysis, they were dialyzed on the corner of the unit, with separation from other patients by $2 \mathrm{~m}$ in all directions. All infected and noninfected patients used surgical masks prior to entering the facility and throughout the treatment. Dialysis staff adhered to infection control measures including the use of N95 or FFP3 mask, disposable gloves, face shields, cap, and more frequent cleaning and disinfection. External surfaces (chairs, beds, tables) and hemodialysis machines were disinfected by sodium hypochlorite solution after each session.

During admission, all patients received 4-h dialysis sessions per week with a similar dialysis prescription: (AutoSub Plus, FMC, Bad Homburg, Germany) in 4008S dialysis monitors, dialyzer surface $1.8 \mathrm{~m}^{2}$. Synthetic high-flux dialyzer membrane (F80, Fresenius Medical Care, Bad
Homburg, Germany) was used in all patients. The standard dialysis bath consisted of sodium, $138 \mathrm{mEq} / \mathrm{l}$; potassium, $2 \mathrm{mEq} / \mathrm{l}$; calcium, $1.75 \mathrm{mmol} / \mathrm{l}$ and bicarbonate, $35 \mathrm{mEq} / \mathrm{l}$. The dialysis prescription was individualized for each patients on admission. $\mathrm{Kt} / \mathrm{V}$ values were calculated for evaluating dialysis adequacy.

Demographic data (age, sex, co-morbidities), history of exposure, symptoms (fever, cough, dyspnea, diarhea, fatique, myalgia, abdominal pain, anosmi), signs, initial and last laboratory test findings, initial electrocardiogram results, computed tomographic(CT) scans of the chest and treatment (including antiviral therapy, antibiotics, corticosteroid therapy, and oxygen support) were obtained from electronic medical records. The laboratory findings of the patients on admission or within $24 \mathrm{~h}$ of admission and on the last visit were evaluated. Outcomes (discharging, invasive mechanical ventilation, ICU care, and death) were assessed.

\section{Hospitalization criteria for COVID-19}

The diagnosis of COVID-19 was made based on the Turkish Ministry of Health COVID-19 guideline. Cases with a positive RT-PCR were described as laboratory-confirmed COVID-19 patients. Patients with clinical symptoms and thorax CT findings of COVID 19 and in whom laboratory diagnosis is negatively accepted as clinically diagnosed COVID 19 patient. According to our national guide, patients who have any of the following criteria were admitted to the hospital: > 50 years old, have an underlying disease (cardiovascular disease, chronic renal diseases, diabetes, hypertension, cancer, chronic pulmonary disease, immunocompression), severe pneumonia (confusion or tachycardia ( $>125$ / $\min$ ) or dyspnea or tachypnea ( $>30 / \mathrm{min})$ or hypotension, $\mathrm{SpO}_{2}<90$, bilateral diffuse pulmonary infiltration on radiologic imaging), sepsis, septic shock, acute renal failure, bad prognostic initial laboratory test (lymphocyte $<800 / \mu$, $\mathrm{CRP}<40 \mathrm{mg} / \mathrm{l}$ ferritin $>500 \mathrm{ng} / \mathrm{ml}$ veya d-dimer $>1000 \mathrm{ng} /$ $\mathrm{ml}$, etc.)

\section{Laboratory examinations}

Initial laboratory examinations including complete blood count, coagulation profile, serum biochemical tests (renal and liver function test, C-reactive protein, creatine kinase, procalcitonin, lactate dehydrogenase (LDH) and electrolytes), myocardial enzymes (troponin) and serum ferritin levels were evaluated. Throat and nasal swab samples of all patients were collected for detection of SARS-CoV-2 RNA using real-time fluorescent reverse transcription-polymerase chain reaction (RT-PCR). If the initial RT-PCR test was negative, nasopharyngeal swabs were taken $24 \mathrm{~h}$ later due to $30-40 \%$ of false negativity of a single swab. Chest CT scan was performed for all inpatients since CT scan was faster and 
more effective than etiologic examination for the screening of COVID-19.

\section{Image interpretation}

Chest CT images were retrieved from the electronic medical records. The typical CT findings for COVID-19 included ground glass opacity (GGO), crazy-paving pattern, consolidation, and mixed pattern. The extent of pulmonary abnormalities on thin-slice CT was evaluated by a conventional semiquantitative scoring system. Each lung was divided into three zones; superior (above the carina), middle (the carina up to the inferior pulmonary vein) and inferior (below the inferior pulmonary vein). Each zone was evaluated for percentage of lung involvement: score $0,0 \%$ involvement; score 1 , less than $25 \%$; score $2,25-50 \%$; score $3,50 \%$ to less than $75 \%$; and score $4,75 \%$ or more. Summation of scores from all six lung zones provided overall CT score (maximal CT score, 24). Patients were divided into three groups according to total CT score: mild $(<5)$, moderate $(5-11)$ and severe (12 or more).

\section{Management of the patients}

All patients received supportive treatment after admission. Vital signs and oxygen saturation were monitored for every four hours; water, electrolyte, and acid-base balance were maintained and the intake volume was restricted. Supplemental oxygen therapy was started at a flow rate of $5 \mathrm{~L} / \mathrm{min}$ immediately if pulse oxygen saturation $<92 \%$ in patients. If standard oxygen therapy fails to keep pulse oxygen saturation $\geq 92 \%$, high flow nasal catheter oxygen or non-invasive ventilation was used. If no improvement was seen with noninvasive mechanical ventilation, patients were evaluated for invasive mechanical ventilation by anesthesiologists.

Medical treatment was arranged according to guidelines of The Ministry of Health of the Government of Turkey Scientific Board. This guideline was modified several times according to epidemiological and national findings. Initially, patients were empirically treated with 5-hydroxychloroquine and/or azithromycin for 5-10 days if there is no contraindication (QT interval $<0.50 \mathrm{msc}$ ). Oseltamivir was added to the treatment if there is suspicion of seasonal influenza. After April 2, 2020, patients were treated with 5-OH-chloroquine and/or favipiravir and/or azithromycin for 5-10 days based on the severity of the disease. Favipiravir was considered for clinically severe patients with pulse oxygen saturation $<90 \%$ in room air, breathing rate $>30$ / min, and radiological findings of bilateral diffuse pneumonia or acute organ dysfunction. If favipiravir was used for initial therapy or added to the treatment on the following days, oseltamivir was not used or stopped, respectively. All patients received thromboprophylaxis. Considering the well-known potential of hydroxychloroquine and azithromycin for increasing QTc, a baseline ECG was performed before starting the treatment and afterward daily. In the case of QTc prolongation, azithromycin was stopped firstly. If QT prolongation persisted, a reduction or discontinuation of 5-OH-chloroquine was considered. Tocilizumab was considered for patients with macrophage activation syndrome (MAS) and methylprednisolone for acute respiratory distress syndrome.

If the patients had one of the following criteria, they were consulted for admission to ICU: dyspnea, respiratory rate $>30 / \mathrm{min}, \mathrm{PaO} 2 / \mathrm{FiO}_{2}<300$, acute hepatic failure, confusion, acute hemorrhagic problem, elevated troponin or arrhythmia, and lactate $>2$ mmol.

Complications (ARDS, MAS, sepsis, shock, acute liver injury, acute heart failure and cardiac injury) were noted.

Patients were discharged after complete resolution of clinical symptoms and withdrawal of oxygen therapy for at least $24 \mathrm{~h}$ and maintained dialysis in our unit for at least 14 days after complete resolution of initial symptoms. If 2 negative PCR results were detected in this period, they were referred back to their initial outpatient center.

\section{Statistical analysis}

NCSS (Number Cruncher Statistical System) 2007 (Kaysville, Utah, USA) program was used for statistical analysis. Descriptive statistical methods (mean, standard deviation, median, frequency, ratio, minimum, maximum) were used while evaluating the study data. The suitability of quantitative data to normal distribution was tested by Kolmogorov-Smirnov, Shapiro-Wilk test and graphical evaluations. Mann-Whitney $U$ test was used for comparisons of two groups of data that did not show normal distribution. Pearson Chi-Square test, Fisher-Freeman-Halton Exact test and Fisher's Exact test were used for comparison of qualitative data. Logistic Regression analysis was examined in multivariate evaluations. Significance was evaluated at the $p<0.05$ level.

\section{Results}

A total of 1958 patients were retrospectively screened and a total of 45 dialyzed patients were detected who were admitted to the hospital, 16 patients had positive RT-PCR test and 29 with negative RT-PCR had typical symptoms and thorax CT findings of viral pneumonia. Dialyzed patients constituted $2.2 \%$ of all patients who were hospitalized for COVID-19 infection.

Two of them were our outpatient maintenance hemodialysis patients and they had close contact with family members with confirmed COVID-19 cases. We do not know the 
incidence of SARS-CoV-2 infection in our hemodialysis facility because the RT-PCR test could only be performed in symptomatic patients. For clinical outcomes, 31 (68.8\%) patients were discharged and 14 patients died with a mortality rate of $31 \%$. The median age of the patients was $65.33 \pm 12.22$ (36-88) years, of whom 24 were 65 years or older. Slightly more than half of the population $(53.7 \%)$ were female and the rate of males in non-survivors was slightly higher than females (9 vs. 5). But no significant difference in age and sex between survivors and non-survivors was seen. The most common primary disease-causing end-stage renal disease was diabetes mellitus $(57.8 \%)$ among patients with known etiology. Many had underlying comorbidities; hypertension was the most common comorbidity $(60 \%)$ and followed by diabetes mellitus, coronary heart disease, and chronic obstructive pulmonary disease. All of the patients underwent dialysis three times per week before the pandemic and the mean hemodialysis vintage was $53.96 \pm 40.6$ months (median 50 months). $77.8 \%$ of the patients used arteriovenous fistula as hemodialysis access and others used tunneled hemodialysis catheters. There was no difference in BMI between the two study groups. $(28.60 \pm 7.96$ vs. $24.50 \pm 4.24 ; p>0.182) . \mathrm{Kt} / \mathrm{V}$ values were similar in the two groups $(1.2 \pm 0.72$ vs. $1.34 \pm 0.74)$. Table 1 summarizes the baseline characteristics of the study population.

Most patients reported at least one of the following symptoms: dyspnea (55.6\%), dry cough (53.3\%), back pain (13.3\%), diarrhea (8.9\%), fatigue (8.9\%), sore throat (4.4\%), headache (4.4\%), taste/smell disorder (2.2\%). On admission, 28 of the patients had oxygen saturation less than $92 \%$ in room air and required high flow oxygen support during hospitalization, including nasal cannula or mask and 27 had body temperature over $37.3{ }^{\circ} \mathrm{C}$. Compared to survivors, non-survivor patients were more likely to have shortness of breath (78.6\% vs. $45.2 \%)$ and tended to have poor oxygen saturation (92.9\% vs. $48.4 \%$ ) (Table 1$)$.

Among PCR positive patients, 2 in the survivor group and 1 in the nonsurvivor group had normal chest CT findings on admission. The most common imaging manifestation was ground-glass opacity (GGO) which was found in $75 \%$ of the patients. The extent of pulmonary abnormalities on thin slice CT was evaluated by a conventional semiquantitative scoring system and termed as light, middle and severe. Radiological findings were classified as mild, moderate or severe in $22 \%, 26.8 \%$, and $31.7 \%$ of cases respectively and no significant difference was observed in score of chest CT performed on the day of hospitalization for the survivors and nonsurvivors. 7 patients had pleural effusion on CT images (Table 1).

No difference in initial laboratory test was observed between survivors and non-survivors, except CRP level that was higher in nonsurvivors $(p=0.017)$. As the disease progressed, significantly higher white blood cell and neutrophil counts, as well as higher level of neutrophile/ lymphocyte ratio, CRP, procalcitonin, Aspartate aminotransferase (AST), alanine aminotransferase (ALT), ferritin, troponin, $\mathrm{LDH}$, creatine kinase, and lower lymphocyte count and serum albumin were observed in nonsurvivors compared to survivors $(p<0.05)$ There was no statistically significant difference for calcium, phosphate, hemoglobin and intact parathyroid hormone values between non-survivors and survivors (Table 2).

All patients were administered thromboprophylaxis at renal doses after admission and one patient who developed pulmonary embolism received a therapeutic dose of heparin. $93.3 \%$ of the patients had hydroxychloroquine, 33 received it with azithromycin. Oseltamivir was given in 25 patients and no adverse effect was observed. Patients with poor oxygen saturation were treated with favipiravir (55.6\%). Many patients received antibacterial therapy, mostly piperacillin-tazobactam. $51.1 \%$ who developed a secondary infection. Three patients received tocilizumab, two had intravenous immunoglobulin, seven ascorbic acid, and two hydrocortisone. Compared to survivors, non-survivors were more likely to receive favipiravir, ascorbic acid ve piperacillin + tazobactam $(p=0.037 ; p=0.023 ; p=0.025$, respectively; $p<0.05$ ). By contrast, the median duration of hydroxychloroquine treatment in non-survivors was shorter than survivors $(p=0.015 ; p<0.05)$ (Table 3$)$.

Fourteen $(31.1 \%)$ of the infected patients were transferred to the ICU in the following days. All received mechanical ventilation. Eleven of them died. The mean time from admission to death was $9.86 \pm 8.87$ days (range 2-35 days) and the cause of death was respiratory failure and ARDS. One patient survived despite the development of MAS. At the end of the study period, 31 patients were discharged alive after an average of $14.9 \pm 9.56$ days (range $3-43$ days). Length of hospital stay was statistically different between non-survivors and survivors ( 7 vs. 13 days, $p=0.030$ ).

When the logistic regression analysis were performed, age and having DM had no significant effect on mortality $(p>0.05)$. Dyspnea and decreased saturation were the independent risk factors affecting mortality $(p<0.05)$. It was found that dyspnea increased mortality by 5.5 times and decreased saturation for 16.5 times (Table 4).

In our study, mortality rates for COVID-19 in hemodialysis patients were estimated to be $31.1 \%$. The probability of in-hospital death was similar in patients with diabetes mellitus or hypertension (Table 1).

\section{Discussion}

HD patients have a higher risk for COVID-19 and its complications than other populations, owing to older age, the presence of multiple co-morbid conditions, and impaired cellular 
Table 1 The baseline characteristics of the patients according to mortality

\begin{tabular}{|c|c|c|c|c|}
\hline & \multirow[b]{2}{*}{$\begin{array}{l}\text { Total }(n=45) \\
n(\%)\end{array}$} & \multicolumn{2}{|l|}{ Mortality } & \multirow[t]{2}{*}{$p$} \\
\hline & & $\begin{array}{l}\text { Survivors }(n=31) \\
n(\%)\end{array}$ & $\begin{array}{l}\text { Nonsurvivors }(n=14) \\
n(\%)\end{array}$ & \\
\hline \multicolumn{5}{|l|}{ Age (years) } \\
\hline Median (Q1-Q3) & $36-88(66)$ & $36-88(66)$ & $46-86(66.5)$ & \multirow[t]{2}{*}{${ }^{\mathrm{a}} 0.606$} \\
\hline Mean \pm SD & $65.33 \pm 12.22$ & $64.48 \pm 12.51$ & $67.21 \pm 11.76$ & \\
\hline \multicolumn{5}{|l|}{ Age groups } \\
\hline$<65$ & $21(46.7)$ & $15(48.4)$ & $6(42.9)$ & \multirow[t]{2}{*}{ b0.731 } \\
\hline$\geq 65$ & $24(53.3)$ & $16(51.6)$ & $8(57.1)$ & \\
\hline \multicolumn{5}{|l|}{ Sex } \\
\hline Female & $24(53.3)$ & $19(61.3)$ & $5(35.7)$ & \multirow[t]{2}{*}{ b0.111 } \\
\hline Male & $21(46.7)$ & $12(38.7)$ & $9(64.3)$ & \\
\hline \multicolumn{5}{|l|}{ Dialysis vintage (months) } \\
\hline Median (Q1-Q3) & $3-156(50)$ & $3-156(50)$ & $6-144(55)$ & \multirow[t]{2}{*}{${ }^{\mathrm{a}} 0.932$} \\
\hline Mean \pm SD & $53.96 \pm 40.68$ & $53.06 \pm 40.86$ & $55.93 \pm 41.73$ & \\
\hline \multicolumn{5}{|l|}{ Body weight (kg) } \\
\hline Median (Q1-Q3) & $52.5-75(64)$ & $54-96.5(63)$ & $52.3-71.8(64.8)$ & \multirow[t]{2}{*}{${ }^{\mathrm{a}} 0.270$} \\
\hline Mean \pm SD & $67.6 \pm 19.06$ & $75.82 \pm 26.52$ & $63.33 \pm 13.43$ & \\
\hline \multicolumn{5}{|l|}{ Body mass index $\left(\mathrm{kg} / \mathrm{m}^{2}\right)$} \\
\hline Median (Q1-Q3) & $21-28.6(24.9)$ & $24.3-34.4(26.9)$ & $20.8-28.3(24.3)$ & \multirow[t]{2}{*}{${ }^{\mathrm{a}} 0.182$} \\
\hline Mean \pm SD & $25.79 \pm 5.88$ & $28.60 \pm 7.96$ & $24.50 \pm 4.24$ & \\
\hline \multicolumn{5}{|l|}{ Co-morbid disease } \\
\hline Diabetes mellitus & $26(57.8)$ & $15(48.4)$ & $11(78.6)$ & ${ }^{\mathrm{b}} 0.058$ \\
\hline Hypertension & $27(60.0)$ & $17(54.8)$ & $10(71.4)$ & b 0.293 \\
\hline Chronic obstructive lung disease & $4(8.9)$ & $4(12.9)$ & $0(0)$ & ${ }^{\mathrm{c}} 0.294$ \\
\hline Coronary heart disease & $20(44.4)$ & $12(38.7)$ & $8(57.1)$ & b 0.249 \\
\hline Others & $21(46.7)$ & $14(45.2)$ & $7(50.0)$ & b 0.763 \\
\hline \multicolumn{5}{|l|}{ Symptoms } \\
\hline Cough & $24(53.3)$ & $15(48.4)$ & $9(64.3)$ & b 0.322 \\
\hline Dyspnea & $25(55.6)$ & $14(45.2)$ & $11(78.6)$ & b $0.037 *$ \\
\hline Back pain & $6(13.3)$ & $3(9.7)$ & $3(21.4)$ & ${ }^{\mathrm{c}} 0.356$ \\
\hline Diarrhea & $4(8.9)$ & $4(12.9)$ & $0(0)$ & ${ }^{\mathrm{c}} 0.294$ \\
\hline Fatigue & $4(8.9)$ & $3(9.7)$ & $1(7.1)$ & ${ }^{\mathrm{c}} 1.000$ \\
\hline Sore throat & $2(4.4)$ & $2(6.5)$ & $0(0)$ & ${ }^{\mathrm{c}} 1.000$ \\
\hline Headache & $2(4.4)$ & $0(0)$ & $2(14.3)$ & ${ }^{\mathrm{c}} 0.092$ \\
\hline Taste/smell disorder & $1(2.2)$ & $1(3.2)$ & $0(0)$ & ${ }^{\mathrm{c}} 1.000$ \\
\hline Low saturation $(<92)$ & $28(62.2)$ & $15(48.4)$ & $13(92.9)$ & ${ }^{\mathrm{b}} 0.004 * *$ \\
\hline \multicolumn{5}{|l|}{ Initial fever } \\
\hline Median (Q1-Q3) & $36-39.5(37.5)$ & $36-39(37.3)$ & $36-39.5(37.8)$ & \multirow[t]{2}{*}{${ }^{\mathrm{a}} 0.277$} \\
\hline Mean \pm SD & $37.32 \pm 0.93$ & $37.22 \pm 0.90$ & $37.56 \pm 0.97$ & \\
\hline \multicolumn{5}{|l|}{ Initial fever $\left(37.3^{\circ} \mathrm{C}\right)$} \\
\hline No & $18(40.0)$ & $14(45.2)$ & $4(28.6)$ & \multirow[t]{2}{*}{ b0.293 } \\
\hline Yes & $27(60.0)$ & $17(54.8)$ & $10(71.4)$ & \\
\hline \multicolumn{5}{|l|}{ Initial systolic BP (mmHg) } \\
\hline Median (Q1-Q3) & $78-189(130)$ & $90-189(120)$ & $78-170(135)$ & \multirow[t]{2}{*}{${ }^{\mathrm{a}} 0.873$} \\
\hline Mean \pm SD & $132.20 \pm 27.69$ & $133.06 \pm 28.58$ & $130.29 \pm 26.54$ & \\
\hline Initial diastolic BP (mmHg) & & & & \\
\hline Median (Q1-Q3) & $50-100(70)$ & $50-100(70)$ & $50-90(75)$ & ${ }^{\mathrm{a}} 0.776$ \\
\hline Mean \pm SD & $71.78 \pm 13.66$ & $71.90 \pm 13.74$ & $71.50 \pm 14.00$ & \\
\hline
\end{tabular}


Table 1 (continued)

\begin{tabular}{|c|c|c|c|c|}
\hline & \multirow[b]{2}{*}{$\begin{array}{l}\text { Total }(n=45) \\
n(\%)\end{array}$} & \multicolumn{2}{|l|}{ Mortality } & \multirow[t]{2}{*}{$p$} \\
\hline & & $\begin{array}{l}\text { Survivors }(n=31) \\
n(\%)\end{array}$ & $\begin{array}{l}\text { Nonsurvivors }(n=14) \\
n(\%)\end{array}$ & \\
\hline \multicolumn{5}{|l|}{ Initial $\mathrm{SO}_{2}$} \\
\hline Median (Q1-Q3) & $80-98(95)$ & $80-98(95)$ & $82-98(94)$ & \multirow[t]{2}{*}{${ }^{\mathrm{a}} 0.300$} \\
\hline Mean \pm SD & $93.49 \pm 4.63$ & $93.84 \pm 4.71$ & $92.71 \pm 4.51$ & \\
\hline \multicolumn{5}{|l|}{ Lenght of stay in hospital } \\
\hline Median (Q1-Q3) & $2-43(11)$ & $3-43(13)$ & $2-35(7)$ & \multirow[t]{2}{*}{${ }^{\mathrm{a}} 0.030^{*}$} \\
\hline Mean \pm SD & $13.33 \pm 9.54$ & $14.9 \pm 9.56$ & $9.86 \pm 8.87$ & \\
\hline \multicolumn{5}{|l|}{ PCR } \\
\hline Negative & $29(64.4)$ & $20(64.5)$ & $9(64.3)$ & \multirow[t]{2}{*}{${ }^{\mathrm{c}} 1.000$} \\
\hline Positive & $16(35.6)$ & $11(35.5)$ & $5(35.7)$ & \\
\hline \multicolumn{5}{|l|}{ Vascular Access } \\
\hline Arteriovenous fistula & $35(77.8)$ & $23(74.2)$ & $12(85.7)$ & \multirow[t]{2}{*}{${ }^{\mathrm{c}} 0.469$} \\
\hline Tunneled hemodialysis catheters & $10(22.2)$ & $8(25.8)$ & $2(14.3)$ & \\
\hline \multicolumn{5}{|l|}{$\mathrm{Kt} / \mathrm{V}$} \\
\hline Median (Q1-Q3) & $1-1.9(1.3)$ & $1-1.7(1.4)$ & $1.3-1.9(1.5)$ & \multirow[t]{2}{*}{0.478} \\
\hline Mean \pm SD & $1.62 \pm 0.34$ & $1.2 \pm 0.72$ & $1.34 \pm 0.74$ & \\
\hline \multicolumn{5}{|l|}{ CT scan } \\
\hline Normal & $2(4.4)$ & $1(3.2)$ & $1(7.1)$ & \multirow[t]{4}{*}{${ }^{\mathrm{d}} 0.697$} \\
\hline Mild & $11(24.4)$ & $9(29.0)$ & $2(14.3)$ & \\
\hline Moderate & $20(44.4)$ & 13 (41.9) & $7(50.0)$ & \\
\hline Severe & $12(26.7)$ & $8(25.8)$ & 4 (28.6) & \\
\hline \multicolumn{5}{|l|}{ Intensive care follow-up } \\
\hline No & $31(68.9)$ & $28(90.3)$ & $3(21.4)$ & \multirow[t]{2}{*}{${ }^{\mathrm{c}} 0.001 * *$} \\
\hline Yes & $14(31.1)$ & $3(9.7)$ & 11(78.6) & \\
\hline
\end{tabular}

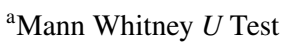

${ }^{\mathrm{b}}$ Pearson Ki-kare Test

${ }^{\text {c}}$ Fisher's Exact Test

${ }^{\mathrm{d}}$ Fisher Freeman Halton Exact Test

$* p<0.05$

$* * p<0.01$

and humoral immune system. Also, unlike patients on home dialysis and peritoneal dialysis, these group of patients has to apply to hemodialysis center every other day, spend time in crowded waiting areas before and after treatment and come together with many patients and dialysis staff in the facility, increasing risk of exposure [1]. There is limited information about the impacts of the COVID-19 epidemic on HD patients. We aimed to add some data to this small information pool by describing presentations, early clinical course, and short-term outcomes of SARS-CoV-2 infection in chronic hemodialysis patients and analyzing prognostic markers for mortality.

Viral nucleic acid detection using RT-PCR is the gold standard in the diagnosis of COVID-19 but its sensitivity may be as low as $50 \%$ possibly because of inadequate viral material in the sample or technical issues during nucleic acid extraction [9]. Several studies have compared the diagnostic accuracy of chest CT scan and RT-PCR and showed that the sensitivity of chest CT was higher than RT-PCR $[10,11]$. Regarding the low sensitivity and relatively long processing time of PCR as well as the rapidly spreading epidemic of COVID-19, we used typical findings of chest CT in combination with exposure history and clinical symptoms for identification and early intervention of the patients with negative RT-PCR tests.

Previous studies indicated that older patients with comorbidities have a higher risk of infection and fatal respiratory complications [12]. Our results revealed that established risk factors in the general population, such as age, male sex, diabetes, coronary heart disease or chronic obstructive lung disease were not associated with higher mortality unlike the Spanish series [13]. There was no difference in dialysis vintage between the study groups and these factors had no significant effect on mortality. 
Table 2 Laboratory findings on admission and discharge
Mortality

Survivors $(n=31)$

Nonsurvivors $(n=14)$

BUN (IQR), mg/dL

Admission

Median (Q1-Q3)

56-192 (95)

Mean \pm SD

$104.74 \pm 36.83$

36-264 (128)

0.059

Discharge

Median (Q1-Q3)

28-217 (76)

Mean \pm SD

$95.00 \pm 48.81$

Creatinine (IQR), mg/dL

Admission

Median (Q1-Q3)

3.1-13.9 (6)

$6.76 \pm 2.63$

4.7-12 (8)

0.148

Mean \pm SD

2-11 (5)

Median (Q1-Q3)

$5.82 \pm 2.45$

0.9-14 (6.3)

0.650

Mean \pm SD

Calcium (IQR), mg/dL

Admission

Median (Q1-Q3)

Mean \pm SD

5.7-12 (8.6)

$8.39 \pm 1.33$

$6.1-9.5(8)$

0.320

Discharge

Median (Q1-Q3)

5.9-9.9 (8.5)

$8.32 \pm 0.96$

$8.04 \pm 0.95$

5.7-9.6 (7.8)

0.141

Mean \pm SD

$7.81 \pm 1.15$

Phosphate (IQR), mg/dL

Admission

Median (Q1-Q3)

2.3-7.9 (4.4)

$4.56 \pm 1.20$

2.1-7 (5.5)

0.287

Mean \pm SD

$4.89 \pm 1.68$

Discharge

Median (Q1-Q3)

2.3-8.9 (4.1)

Mean \pm SD

2.1-7 (5.5)

0.463

ALT (Alanine aminotransferase)
$4.34 \pm 1.70$

AST (Aspartate aminotransferase)

Admission

Median (Q1-Q3)

9-180 (20)

$31.81 \pm 32.83$

Mean \pm SD

$7-78(16)$

Median (Q1-Q3)

$19.19 \pm 13.33$

Mean \pm SD

Admission

Median (Q1-Q3)

2-126 (13)

$17.77 \pm 22.91$

Mean \pm SD

Discharge

Median (Q1-Q3) 3-29 (10)

Mean \pm SD

$11.32 \pm 5.96$

LDH

Admission

Median (Q1-Q3) 178-696 (296)

Mean \pm SD $\quad 316.94 \pm 129.08$

$140-515$ (235.5)

$249.57 \pm 83.32$

$4.89 \pm 1.68$

12-89 (29)

0.185

$37.79 \pm 23.86$

14-499 (40.5)

$0.001 * *$

$96.64 \pm 128.42$

5-116 (17.5)

0.103

$26.64 \pm 29.22$

5-204 (25)

$0.001 * *$

$45.79 \pm 55.73$

219-720 (326.5)

0.138

Discharge

Median (Q1-Q3)

Mean $\pm S D$
$388.64 \pm 163.85$

116-1199 (361)

$0.001 * *$ $482.08 \pm 288.26$ 
Table 2 (continued)

\begin{tabular}{|c|c|c|c|}
\hline & \multicolumn{2}{|l|}{ Mortality } & \multirow[t]{2}{*}{${ }^{\mathrm{a} p} p$} \\
\hline & Survivors $(n=31)$ & Nonsurvivors $(n=14)$ & \\
\hline \multicolumn{4}{|l|}{ Troponin I (ng/mL) } \\
\hline \multicolumn{4}{|l|}{ Admission } \\
\hline Median (Q1-Q3) & $6.3-24,800(35)$ & $9-2659(60)$ & \multirow[t]{2}{*}{0.398} \\
\hline Mean \pm SD & $1161.14 \pm 4570.57$ & $239.50 \pm 696.89$ & \\
\hline \multicolumn{4}{|l|}{ Discharge } \\
\hline Median (Q1-Q3) & $3-347(25)$ & $12-12,925(66)$ & \multirow[t]{2}{*}{$0.002 * *$} \\
\hline Mean \pm SD & $42.30 \pm 67.83$ & $1239.64 \pm 3875.76$ & \\
\hline \multicolumn{4}{|l|}{ CK (U/L) } \\
\hline \multicolumn{4}{|l|}{ Admission } \\
\hline Median (Q1-Q3) & $15-766(99.5)$ & $14-666(138)$ & \multirow[t]{2}{*}{0.177} \\
\hline Mean \pm SD & $130.27 \pm 158.22$ & $207.92 \pm 195.71$ & \\
\hline \multicolumn{4}{|l|}{ Discharge } \\
\hline Median (Q1-Q3) & $10-181(30)$ & $15-400(169)$ & \multirow[t]{2}{*}{$0.010 *$} \\
\hline Mean \pm SD & $44.93 \pm 40.35$ & $165.44 \pm 136.5$ & \\
\hline \multicolumn{4}{|l|}{ T. PROT (g/L) } \\
\hline \multicolumn{4}{|l|}{ Admission } \\
\hline Median (Q1-Q3) & $54-78(68)$ & $52-78(71)$ & \multirow[t]{2}{*}{0.453} \\
\hline Mean $\pm \mathrm{SD}$ & $68.32 \pm 5.09$ & $68.50 \pm 7.91$ & \\
\hline \multicolumn{4}{|l|}{ Discharge } \\
\hline Median (Q1-Q3) & $55-78(63.5)$ & $34-76(56)$ & \multirow[t]{2}{*}{0.167} \\
\hline Mean \pm SD & $64.13 \pm 6.34$ & $58.17 \pm 13.33$ & \\
\hline \multicolumn{4}{|l|}{$\operatorname{Albumin}(\mathrm{g} / \mathrm{L})$} \\
\hline \multicolumn{4}{|l|}{ Admission } \\
\hline Median (Q1-Q3) & $22-41(35)$ & $17-41(34.5)$ & \multirow[t]{2}{*}{0.721} \\
\hline Mean \pm SD & $34.23 \pm 4.31$ & $32.93 \pm 6.11$ & \\
\hline \multicolumn{4}{|l|}{ Discharge } \\
\hline Median (Q1-Q3) & $23-41(32)$ & $17-36(24)$ & \multirow[t]{2}{*}{$0.001 * *$} \\
\hline Mean $\pm \mathrm{SD}$ & $31.47 \pm 4.38$ & $24.67 \pm 6.26$ & \\
\hline Hemoglobin (IQR), g/ & & & \\
\hline Admission & & & \\
\hline Median (Q1-Q3) & 8-15 (10.9) & $8.1-14(10.9)$ & 0.787 \\
\hline Mean \pm SD & $10.76 \pm 1.54$ & $10.92 \pm 1.78$ & \\
\hline Discharge & & & \\
\hline Median (Q1-Q3) & $7.4-12.5(9.4)$ & $7.2-12.4(10.6)$ & 0.134 \\
\hline Mean \pm SD & $9.58 \pm 1.31$ & $10.29 \pm 1.60$ & \\
\hline Neutrophils $\left(10^{3} / \mu \mathrm{L}\right)$ & & & \\
\hline Admission & & & \\
\hline Median (Q1-Q3) & $1940-15,300$ (4890) & $1530-11,950$ (4035) & 0.391 \\
\hline Mean \pm SD & $6012.58 \pm 3501.01$ & $5190.00 \pm 3267.72$ & \\
\hline Discharge & & & \\
\hline Median (Q1-Q3) & $1630-10,300(3900)$ & $1750-23,500(8100)$ & $0.010 *$ \\
\hline Mean \pm SD & $4606.13 \pm 2255.11$ & $8720.00 \pm 5607.18$ & \\
\hline Lymphocytes (IQR), & & & \\
\hline Admission & & & \\
\hline Median (Q1-Q3) & $220-1750(850)$ & $400-2000(865)$ & 0.641 \\
\hline Mean \pm SD & $886.65 \pm 386.76$ & $972.86 \pm 434.52$ & \\
\hline Discharge & & & \\
\hline Median (Q1-Q3) & $240-2700(1370)$ & $280-2390(865)$ & $0.013 *$ \\
\hline Mean \pm SD & $1349.77 \pm 559.90$ & $932.86 \pm 558.85$ & \\
\hline
\end{tabular}


Table 2 (continued)

\begin{tabular}{|c|c|c|c|}
\hline & \multicolumn{2}{|l|}{ Mortality } & \multirow[t]{2}{*}{${ }^{\mathrm{a}} p$} \\
\hline & Survivors $(n=31)$ & Nonsurvivors $(n=14)$ & \\
\hline \multicolumn{4}{|c|}{ Neutrophils/Lymphocytes ratio; $n(\%)$} \\
\hline \multicolumn{4}{|l|}{ Admission } \\
\hline Median (Q1-Q3) & $1.7-64.1(5.3)$ & $1.1-13(6.3)$ & \multirow[t]{2}{*}{0.641} \\
\hline Mean \pm SD & $9.64 \pm 12.25$ & $6.37 \pm 4.22$ & \\
\hline \multicolumn{4}{|l|}{ Discharge } \\
\hline Median (Q1-Q3) & $0.9-10.3(3.8)$ & $2-27.1(10.2)$ & \multirow[t]{2}{*}{$0.001 * *$} \\
\hline Mean \pm SD & $3.88 \pm 2.08$ & $11.52 \pm 7.57$ & \\
\hline \multicolumn{4}{|c|}{ Neutrophils/Lymphocytes ratio; $n(\%)$} \\
\hline \multicolumn{4}{|l|}{ Admission } \\
\hline $\mathrm{NLR} \geq 3.5$ & $25(80.6)$ & $8(57.1)$ & \multirow[t]{2}{*}{${ }^{\mathrm{c}} 0.147$} \\
\hline NLR $<3.5$ & $6(19.4)$ & $6(42.9)$ & \\
\hline \multicolumn{4}{|l|}{ Discharge } \\
\hline $\mathrm{NLR} \geq 3.5$ & $17(54.8)$ & $12(85.7)$ & \multirow[t]{2}{*}{${ }^{\mathrm{c}} 0.090$} \\
\hline NLR $<3.5$ & $14(45.2)$ & $2(14.3)$ & \\
\hline \multicolumn{4}{|l|}{ WBC (IQR), $10^{3} / \mu \mathrm{L}$} \\
\hline \multicolumn{4}{|l|}{ Admission } \\
\hline Median (Q1-Q3) & $2.9-12,000(6.9)$ & $2.6-11,000(8.9)$ & \multirow[t]{2}{*}{0.797} \\
\hline Mean \pm SD & $1415.87 \pm 3438.15$ & $1890.63 \pm 3552.44$ & \\
\hline \multicolumn{4}{|l|}{ Discharge } \\
\hline Median (Q1-Q3) & $2.5-13,000(6.4)$ & $4.8-26,000(11.4)$ & \multirow[t]{2}{*}{$0.026^{*}$} \\
\hline Mean \pm SD & $1843.92 \pm 4280.18$ & $3090.72 \pm 7785.84$ & \\
\hline \multicolumn{4}{|l|}{ Platelets (IQR), $10^{3} / \mu \mathrm{L}$} \\
\hline \multicolumn{4}{|l|}{ Admission } \\
\hline Median (Q1-Q3) & $69.0-426.0(161.0)$ & $93.0-315.0(149.0)$ & \multirow[t]{2}{*}{0.633} \\
\hline Mean \pm SD & $186.48 \pm 84.94$ & $177.64 \pm 79.26$ & \\
\hline \multicolumn{4}{|l|}{ Discharge } \\
\hline Median (Q1-Q3) & $64-643$ (219) & $38-365(211)$ & \multirow[t]{2}{*}{0.345} \\
\hline Mean \pm SD & $249.90 \pm 121.53$ & $208.21 \pm 99.81$ & \\
\hline Ferritin (IQR), ng/mL & & & \\
\hline Admission & & & \\
\hline Median (Q1-Q3) & $81-9635$ (708) & 284-9635 (790) & 0.321 \\
\hline Mean \pm SD & $1447.97 \pm 2225.26$ & $1956.43 \pm 2576.10$ & \\
\hline Discharge & & & \\
\hline Median (Q1-Q3) & $102-2809(698)$ & $523-15,000(3733.5)$ & $0.002 * *$ \\
\hline Mean \pm SD & $799.62 \pm 556.38$ & $5693.83 \pm 5766.18$ & \\
\hline C-reactive protein (IQ & & & \\
\hline Admission & & & \\
\hline Median (Q1-Q3) & $11-328(60.0)$ & $26-335(144.5)$ & $0.017^{*}$ \\
\hline Mean \pm SD & $85.52 \pm 73.61$ & $141.71 \pm 83.67$ & \\
\hline Discharge & & & \\
\hline Median (Q1-Q3) & $3.9-133(25.5)$ & $12-430(205.5)$ & $0.001 * *$ \\
\hline Mean \pm SD & $37.01 \pm 31.73$ & $214.29 \pm 116.24$ & \\
\hline Procalcitonin (IQR), $\mathrm{r}$ & & & \\
\hline Admission & & & \\
\hline Median (Q1-Q3) & $0.2-77(1.1)$ & $0.4-20(1.2)$ & 0.212 \\
\hline Mean \pm SD & $5.41 \pm 15.51$ & $4.70 \pm 6.46$ & \\
\hline Discharge & & & \\
\hline Median (Q1-Q3) & $0.1-6.3(0.6)$ & $0.7-35(2.1)$ & $0.001 * *$ \\
\hline Mean \pm SD & $0.93 \pm 1.33$ & $7.40 \pm 10.19$ & \\
\hline
\end{tabular}


Table 2 (continued)

\begin{tabular}{|c|c|c|c|}
\hline & \multicolumn{2}{|l|}{ Mortality } & \multirow[t]{2}{*}{${ }^{\mathrm{a}} p$} \\
\hline & Survivors $(n=31)$ & Nonsurvivors $(n=14)$ & \\
\hline \multicolumn{4}{|c|}{ D-dimers (IQR), $\mu \mathrm{g} / \mathrm{mL}$ ) } \\
\hline \multicolumn{4}{|l|}{ Admission } \\
\hline Median (Q1-Q3) & $0.1-8.5(0.7)$ & $0.1-5.1(0.8)$ & \multirow[t]{2}{*}{0.791} \\
\hline Mean \pm SD & $1.15 \pm 1.54$ & $1.28 \pm 1.37$ & \\
\hline \multicolumn{4}{|l|}{ Discharge } \\
\hline Median (Q1-Q3) & $0-5.2(0.7)$ & $0.2-7.5(0.7)$ & \multirow[t]{2}{*}{0.650} \\
\hline Mean \pm SD & $1.03 \pm 0.97$ & $1.65 \pm 2.39$ & \\
\hline \multicolumn{4}{|l|}{ Fibrinogen (mg/dL) } \\
\hline \multicolumn{4}{|l|}{ Admission } \\
\hline Median (Q1-Q3) & $332-786(505)$ & $216-696(472)$ & \multirow[t]{2}{*}{0.795} \\
\hline Mean \pm SD & $500.07 \pm 93.03$ & $477.50 \pm 134.81$ & \\
\hline \multicolumn{4}{|l|}{ Discharge } \\
\hline Median (Q1-Q3) & $203-634(440)$ & $330-745(582)$ & \multirow[t]{2}{*}{0.145} \\
\hline Mean \pm SD & $443.43 \pm 91.89$ & $539.00 \pm 152.18$ & \\
\hline \multicolumn{4}{|c|}{ Intact parathyroid hormone $(\mathrm{pg} / \mathrm{mL})$} \\
\hline \multicolumn{4}{|l|}{ Admission } \\
\hline Median (Q1-Q3) & $352(306-594)$ & $343(168-552)$ & \multirow[t]{2}{*}{0.414} \\
\hline Mean \pm SD & $458.45 \pm 273.31$ & $411.29 \pm 352.82$ & \\
\hline \multicolumn{4}{|c|}{$C R P$ C-reactive protein, $C T$ computed tomography, $L D H$ lactate dehydrogenase } \\
\hline \multicolumn{4}{|c|}{${ }^{a}$ Mann-Whitney $U$ Test } \\
\hline \multicolumn{4}{|l|}{ 'Fisher's Exact Test } \\
\hline \multicolumn{4}{|l|}{$* * p<0.01$} \\
\hline$* p<0.05$ & & & \\
\hline
\end{tabular}

Since the approach to screen subjects either with or without symptoms was differed among countries, the clinical spectrum of the disease varied in the reports related to this issue. Different from Chinese study on HD population in which the majority of the infected patients experience only mild disease or no symptoms, all participants in our study were symptomatic since we screened only patients with a high index of suspicion for COVID-19 as a national policy. We found that patients mostly complained of fever, dyspnea, and dry cough. In comparison with patients who survived, non-survivors were more dyspneic and had poor oxygen saturation, and more likely to progress to ARDS [6]. In our study, it was found that dyspnea increased mortality by 5,5 times and decreased saturation (Oxygen saturation $<90 \%$ ) by 16.5 times.

Our population rarely suffered from gastrointestinal symptoms and this data contrast with an initial case report of Wang et al. in which $80 \%$ of the patient presented with diarrhea. The reported incidence of diarrhea in patients with COVID-19 ranged from $2 \%$ to $49.5 \%$ in the literature [14].

Previously, along with neutrophilia, leukocytosis, lymphopenia, increased values of CRP, LDH, total bilirubin, AST, creatinine, cardiac biomarkers, prothrombin time (PT), D-dimer, and procalcitonin had been found to be associated with severe disease and mortality in general populations with COVID-19 [15]. D-dimer levels are probably not good predictors of mortality in our study population, since elevated levels have been described in chronic HD patients in stable conditions and D-dimer is cleared with dialysis lowering its concentration independent of disease states.

We found that CT abnormalities suggestive of pneumonia were present in $95.5 \%$ of the patients, among whom $95.5 \%$ of chest CT scans showed bilateral lung involvement. Seven euvolemic patients had pleural effusion which is seen rarely in later stage of COVID-19. A previously published study indicated that higher chest CT scores are associated with a higher mortality rate, $\mathrm{CT}$ images were taken at least 6 days since symptom onset may contain more prognostic information than images taken at an earlier period [16]. Our analysis revealed that for both survivors and the chest CT scores were not significantly different on admission and no link was determined between chest CT score and mortality, similar to other cohorts $[8,13,17]$. Owing to the study design, we did not follow-up CT imaging, except for clinically deteriorating cases.

We applied the same treatment protocol used for the general population in Turkey after renal dosage adjusted. As mentioned before, the drugs have been modified according to the changes in the national scientific board guideline. $93.3 \%$ of the patients received hydroxychloroquine, $82 \%$ 
Table 3 Treatments given to the patients

\begin{tabular}{|c|c|c|c|c|}
\hline & \multirow[b]{2}{*}{$\begin{array}{l}\text { Total }(n=45) \\
n(\%)\end{array}$} & \multicolumn{2}{|l|}{ Mortality } & \multirow[t]{2}{*}{$p$} \\
\hline & & $\begin{array}{l}\text { Survivors }(n=31) \\
n(\%)\end{array}$ & $\begin{array}{l}\text { Nonsurvivors }(n=14) \\
n(\%)\end{array}$ & \\
\hline \multicolumn{5}{|l|}{ Hydroxychloroquine } \\
\hline No & $3(6.7)$ & $1(3.2)$ & $2(14.3)$ & \multirow[t]{2}{*}{${ }^{\mathrm{c}} 0.224$} \\
\hline Yes & $42(93.3)$ & $30(96.8)$ & $12(85.7)$ & \\
\hline \multicolumn{5}{|c|}{ Duration of Hydroxychloroquine } \\
\hline Median (Q1-Q3) & $0-15(5)$ & $0-15(6)$ & $0-10(4)$ & \multirow[t]{2}{*}{${ }^{\mathrm{a}} 0.015^{*}$} \\
\hline Mean \pm SD & $5.73 \pm 3.07$ & $6.48 \pm 2.91$ & $4.07 \pm 2.84$ & \\
\hline \multicolumn{5}{|l|}{ Azithromycin } \\
\hline No & $12(26.7)$ & 7 (22.6) & $5(35.7)$ & \multirow[t]{2}{*}{${ }^{\mathrm{c}} 0.470$} \\
\hline Yes & $33(73.3)$ & $24(77.4)$ & $9(64.3)$ & \\
\hline \multicolumn{5}{|l|}{ Oseltamivir } \\
\hline No & $20(44.4)$ & $14(45.2)$ & $6(42.9)$ & \multirow[t]{2}{*}{ b 0.885} \\
\hline Yes & $25(55.6)$ & $17(54.8)$ & $8(57.1)$ & \\
\hline \multicolumn{5}{|l|}{ Favipiravir } \\
\hline No & $20(44.4)$ & $17(54.8)$ & $3(21.4)$ & \multirow[t]{2}{*}{ b $0.037^{*}$} \\
\hline Yes & $25(55.6)$ & $14(45.2)$ & $11(78.6)$ & \\
\hline \multicolumn{5}{|l|}{ Tocilizumab } \\
\hline No & $42(93.3)$ & $30(96.8)$ & $12(85.7)$ & \multirow[t]{2}{*}{${ }^{c} 0.224$} \\
\hline Yes & $3(6.7)$ & $1(3.2)$ & $2(14.3)$ & \\
\hline \multicolumn{5}{|c|}{ Intravenous immunglobulin } \\
\hline No & $43(95.6)$ & $31(100)$ & $12(85.7)$ & \multirow[t]{2}{*}{${ }^{\mathrm{c}} 0.092$} \\
\hline Yes & $2(4.4)$ & $0(0)$ & $2(14.3)$ & \\
\hline \multicolumn{5}{|l|}{ Ascorbic acid } \\
\hline No & $38(84.4)$ & $29(93.5)$ & $9(64.3)$ & \multirow[t]{2}{*}{${ }^{\mathrm{c}} 0.023^{*}$} \\
\hline Yes & $7(15.6)$ & $2(6.5)$ & $5(35.7)$ & \\
\hline \multicolumn{5}{|l|}{ Lopinavir/ritonavir } \\
\hline No & $42(93.3)$ & $30(96.8)$ & $12(85.7)$ & \multirow[t]{2}{*}{${ }^{\mathrm{c}} 0.224$} \\
\hline Yes & $3(6.7)$ & $1(3.2)$ & $2(14.3)$ & \\
\hline \multicolumn{5}{|l|}{ Hydrocortisone } \\
\hline No & 43 (95.6) & $30(96.8)$ & $13(92.9)$ & ${ }^{c} 0.530$ \\
\hline Yes & $2(4.4)$ & $1(3.2)$ & $1(7.1)$ & \\
\hline Piperacillin-tazobac & & & & \\
\hline No & $27(60)$ & $22(71.0)$ & $5(35.7)$ & b $0.025^{*}$ \\
\hline Yes & $18(40)$ & $9(29.0)$ & $9(64.3)$ & \\
\hline Vancomycin & & & & \\
\hline No & $39(86.7)$ & $28(90.3)$ & $11(78.6)$ & ${ }^{c} 0.356$ \\
\hline Yes & $6(13.3)$ & $3(9.7)$ & $3(21.4)$ & \\
\hline Colistin & & & & \\
\hline No & $43(95.6)$ & $31(100)$ & $12(85.7)$ & ${ }^{c} 0.092$ \\
\hline Yes & $2(4.4)$ & $0(0)$ & $2(14.3)$ & \\
\hline Meropenem & & & & \\
\hline No & $37(82.2)$ & $27(87.1)$ & $10(71.4)$ & ${ }^{\mathrm{c}} 0.231$ \\
\hline Yes & $8(17.8)$ & 4 (12.9) & 4 (28.6) & \\
\hline Teicoplanin & & & & \\
\hline No & $38(84.4)$ & $28(90.3)$ & $10(71.4)$ & ${ }^{\mathrm{c}} 0.180$ \\
\hline Yes & 7 (15.6) & $3(9.7)$ & 4 (28.6) & \\
\hline Ceftriaxone & & & & \\
\hline No & $32(71.1)$ & $20(64.5)$ & $12(85.7)$ & ${ }^{\mathrm{c}} 0.178$ \\
\hline Yes & $13(28.9)$ & $11(35.5)$ & $2(14.3)$ & \\
\hline
\end{tabular}


Table 3 (continued)

\begin{tabular}{lllll}
\hline & & Mortality & $p$ \\
\cline { 3 - 4 } & Total $(n=45)$ & Survivors $(n=31)$ & Nonsurvivors $(n=14)$ & \\
& $n(\%)$ & $n(\%)$ & $n(\%)$ & \\
\hline Linezolid & & & $12(85.7)$ & \\
No & $40(88.9)$ & $28(90.3)$ & $2(14.3)$ & \\
Yes & $5(11.1)$ & $3(9.7)$ & & \\
Secondary infection & & & $4(28.6)$ & ${ }^{\mathrm{b}} 0.067$ \\
No & $22(48.9)$ & $18(58.1)$ & $10(71.4)$ & \\
Yes & $23(51.1)$ & $13(41.9)$ & & \\
\hline
\end{tabular}

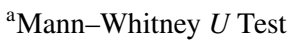

${ }^{\mathrm{b}}$ Pearson Ki-kare Test

${ }^{\text {c}}$ Fisher's Exact Test

$* p<0.05$

$* * p<0.01$

received it with antiviral treatment including oseltamivir and favipiravir, and $73 \%$ with azithromycin. Compared to survivors, favipiravir was mostly used in non-survivors because they tended to have the progression of severe pneumonia and acute organ dysfunction. Changes in treatment modalities, small sample size and lack of control groups in our cohort did not allow us to reach any conclusions on the potential efficacy of these treatments [6].

The mortality rate in our population was higher than that of the Chinese cohort (30.5\% vs. 16.2\%) but they screened all HD patients with and without symptoms and most of them had mild disease. Mortality reported in other series from Newyork, Paris, Spain, and Italy were similar to our result $(25,28,30$, and $27.3 \%$, respectively) $[7,8,13,17]$. The rate of admission to ICU was $31.1 \%$, ICU mortality was $78.6 \%$ in our cohort.

The main limitations of our study are the retrospective nature of the design and lack of some information about the demographic data of the patients. Although our cohort consisted of a small number of patients in a single-center, our findings were consistent with other series [7, 8, 17]. Lastly, our study was limited by a short follow-up period but all of the participants either died or were discharged at the data cut off.

Table 4 Logistic regression analysis of factors that affect mortality

\begin{tabular}{llrrr}
\hline & $p$ & ODDS & \multicolumn{2}{c}{$95 \%$ CI ODDS } \\
\cline { 4 - 5 } & & & Lower & Upper \\
\hline Diabetes mellitus & 0.172 & 3.830 & 0.558 & 26.294 \\
Dyspnea & $0.036^{*}$ & 5.561 & 1.118 & 27.654 \\
Oxygen saturation $<90 \%$ & $0.013^{*}$ & 16.576 & 1.788 & 153.663 \\
Age $>65$ & 0.302 & 2.535 & 0.433 & 14.833 \\
\hline
\end{tabular}

${ }^{*} p<0.05$

\section{Conclusion}

Our study indicates that COVID-19 has a higher mortality rate in HD patients compared to the general population and the risk for death from COVID-19 can be predicted by disease presentation and follow-up of unfavorable prognostic markers by serial blood sampling.

Acknowledgements We thank Emire Bor, EMPIAR Statistics, for performing statistical analysis of the study.

\section{Compliance with ethical standards}

Conflict of interest This study was not supported by any third party and the work was received any financial support. Each author read the manuscript and agree with this submission. The authors declare that there is no conflict of interest with regard to the publication of this paper.

\section{References}

1. Kliger AS, Cozzolino M, Jha V, Harbert G, Alp Ikizler T (2020) Managing the COVID-19 pandemic: international comparisons in dialysis patients. Kidney Int 98(1):12-16. https://doi. org/10.1016/j.kint.2020.04.007

2. Xu J, Zhao S, Teng T, Abdalla AE, Zhu W, Xie L, Wang Y, Guo X (2020) Systematic comparison of two animal-to-human transmitted human coronaviruses: SARS-CoV-2 and SARS-CoV. Viruses 12(2):244. https://doi.org/10.3390/v12020244

3. Wu Z, McGoogan JM (2020) Characteristics of and important lessons from the coronavirus disease 2019 (COVID-19) outbreak in China: summary of a report of 72314 cases from the Chinese. JAMA 323(13):1239-1242. https://doi.org/10.1001/ jama.2020.2648

4. Wang D, Hu B, Hu C, Zhu F, Liu X, Zhang J, Wang B et al (2020) Clinical characteristics of 138 hospitalized patients with 2019 novel coronavirus-infected pneumonia in Wuhan, China. JAMA 323(11):1061-1069. https://doi.org/10.1001/jama.2020.1585 (PMCID: PMC7042881) 
5. Kang YJ (2020) Mortality rate of infection with COVID-19 in Korea from the perspective of underlying disease. Disaster Med Public Health Preparedness 31:1-3. https://doi.org/10.1017/ dmp.2020.60

6. Ma Y, Diao B, Lv X, Zhu J, Liang W, Liu L et al. (2020) 2019 novel coronavirus disease in hemodialysis (HD) patients: report from one HD center in Wuhan, China. MedRxiv, medrxiv.org

7. Fisher M, Yunes M, Mokrzycki MH, Golestaneh L, Alahiri E, Coco M (2020) Chronic hemodialysis patients hospitalized with COVID-19-short-term outcomes in Bronx, New York. J Kidney 3601(8):755-762. https://doi.org/10.34067/KID.0003672020

8. Tortonese S, Scriabine I, Anjou L, Loens C, Michon A, Benabdelhak M, Ouali S et al (2020) COVID-19 in patients on maintenance dialysis in the Paris Region. Kidney Int Rep 5(9):1535-1544. https ://doi.org/10.1016/j.ekir.2020.07.016

9. Zhang S, Li H, Huang S, You W, Sun H (2020) High-resolution computed tomography features of 17 cases of coronavirus disease 2019 in Sichuan province. China Eur Respir J 55(4):2000334. https://doi.org/10.1183/13993003.00334-2020

10. Han R, Huang L, Jiang H, Dong J, Peng H, Zhang D (2020) Early clinical and CT manifestations of coronavirus disease 2019 (COVID-19) pneumonia. AJR Am J Roentgenol 215(2):338-343. https://doi.org/10.2214/AJR.20.22961

11. Pan Y, Guan H, Zhou S, Wang Y, Li Q, Zhu T, Hu Q, Xia L (2020) Initial CT findings and temporal changes in patients with the novel coronavirus pneumonia (2019-nCoV): a study of 63 patients in Wuhan, China. Eur Radiol 13:1-4. https://doi.org/10.1007/s0033 0-020-06731-x

12. Chen N, Zhou M, Dong X, Qu J, Gong F, Han Y et al (2020) Epidemiological and clinical characteristics of 99 cases of 2019 novel coronavirus pneumonia in Wuhan, China: a descriptive study. Lancet 395(10223):507-513. https://doi.org/10.1016/S0140 $-6736(20) 30211-7$

13. Goicoechea M, Cámara LAS, Macías N, Morales AM, Rojas AG, Bascuñana A, Arroyo D (2020) COVID-19: clinical course and outcomes of 36 hemodialysis patients in Spain. Kidney Int 98(1):27-34. https://doi.org/10.1016/j.kint.2020.04.031

14. Wang F, Zheng S, Zheng C, Sun X (2020) Attaching clinical significance to COVID-19-associated diarrhea. Life Sci 260:118312. https://doi.org/10.1016/j.lfs.2020.118312

15. Bonetti G, Manelli B, Patroni A, Bettinardi A, Borrelli G, Fiordalisi $\mathrm{G}$ et al (2020) Laboratory predictors of death from coronavirus disease 2019 (COVID-19) in the area of Valcamonica, Italy. Clin Chem Lab Med 58(7):1100-1105. https://doi.org/10.1515/ cclm-2020-0459

16. Salehi S, Abedi A, Balakrishnan S, Gholamrezanezhad A (2020) Coronavirus disease 2019 (COVID-19): a systematic review of imaging findings in 919 patients. AJR Am J Roentgenol 215(1):87-93. https://doi.org/10.2214/AJR.20.23034

17. Alberici A, Delbarba E, Manenti EL, Valerio F, Pola A (2020) A report from the Brescia Renal COVID task force on the clinical characteristics and short-term outcome of hemodialysis patients with SARS-CoV-2 infection. Kidney Int 98(1):20-26. https://doi. org/10.1016/j.kint.2020.04.030

Publisher's Note Springer Nature remains neutral with regard to jurisdictional claims in published maps and institutional affiliations. 